37.

\section{Mechanism of Injury is Not a Factor in Prehospital Clinical Evaluation of Potential Spine Injury}

Robert M. Domeier, $M D,{ }^{1 *}$ Razuden W. Evans, $M D, P h D,{ }^{1}$ Robert A. Swor, DO, ${ }^{2} J$. Brian Hancock, MD, ${ }^{3}$ William Fales, $M D,{ }^{4}$ Jon Krohmer, $M D,{ }^{5}$ Shirley M Frederiksen, $R N, M S^{1}$

1. University of Michigan/St. Joseph Mercy Emergency

Medicine Residency, Ann Arbor, Michigan USA

2) William Beaumont Hospital, Royal Oak, Michigan USA

3) Michigan State University College of Human Medicine, Sagnigaw, Michigan USA

4) Michigan State University, Kalamazoo Center for Medical Studies, Kalamazoo, Michigan USA

5) Kent County EMS, Michigan State University, College of Human Medicine, Grand Rapids, Michigan USA

Objective: Traditional EMS teaching identifies mechanism of injury as an important predictor of spine injury. Clinical criteria to select patients for immobilization are being studied in Michigan and have been implemented in Maine. Maine requires automatic immobilization of patients with "a positive mechanism" clearly capable of producing spine injury. The purpose of this study is to determine if mechanism of injury effects the ability of clinical criteria to select patients with spine injury.

Design: Multicenter Prospective Cohort.

Methods: EMS personnel completed a check-off data sheet on out-of-hospital spine immobilized patients. Data included mechanism of injury and yes/no determinations of the clinical criteria: altered mental status, neurologic deficit, evidence of intoxication, spinal pain or tenderness, and suspected extremity fracture. Hospital outcome data included confirmation of spine injury and treatment required. Mechanisms of injury were tabulated and rates of spine injury for each mechanism was calculated. The patients were divided into high-risk and low-risk groups.

Results: Data was collected on 6,500 patients. There were 213 (3.3\%) patients with spine injuries identified. There were 1,065 patients with $100(9.4 \%)$ injuries in the high-risk mechanism group, and 5435 patients with $113(2 \%)$ injuries in the low-risk group. Clinical criteria identified 96 of $100(96 \%)$ injuries in the high risk mechanism group and 106 of 113 (94\%) in the low-risk group.

Conclusion: Mechanism of injury does not effect the ability of clinical criteria to predict spine injury in this population.
40. MVCs: Five Most Frequent Sources of Injury John E. Gough, MD, * Richard C. Hunt, MD

Department of Emergency Medicine, East Carolina University School of Medicine, Greenville, North Carolina USA

Purpose: To determine the most frequent sources of injuries from the interior of motor vehicles involved in crashes.

Methods: We searched the National Highway Traffic Safety Administration's National Accident Sampling System to determine the most frequent sources of injuries. This database includes sources of injuries resulting from crashes from January 1, 1991 to December 31, 1992.

Results: During the study period there were 59,909 injuries resulting from 9,704 crashes. The most frequent sources of injuries were:

\begin{tabular}{|c|c|c|}
\hline Windshield & $5,772 / 59,909$ & $(9.6 \%)$ \\
\hline Left instrument panel & $5,516 / 59,909$ & $(9.2 \%)$ \\
\hline $\begin{array}{l}\text { Steering wheel rim (not } \\
\text { including wheel hub/spoke or } \\
\text { steering wheel combination) }\end{array}$ & $4,101 / 59,909$ & $(6.8 \%)$ \\
\hline Belt webbing & $3,754 / 59,909$ & $(6.3 \%)$ \\
\hline Right instrument panel & $2,690 / 59,909$ & $(4.5 \%)$ \\
\hline
\end{tabular}

Conclusions: Windshield and steering wheel rim damage are commonly observed and reported by EMTs to emergency department personnel. These data confirm the importance of this information. These data also show that the instrument panel and belt webbing are frequent sources of injury, and should also be observed and reported by EMTs to emergency department personnel. 